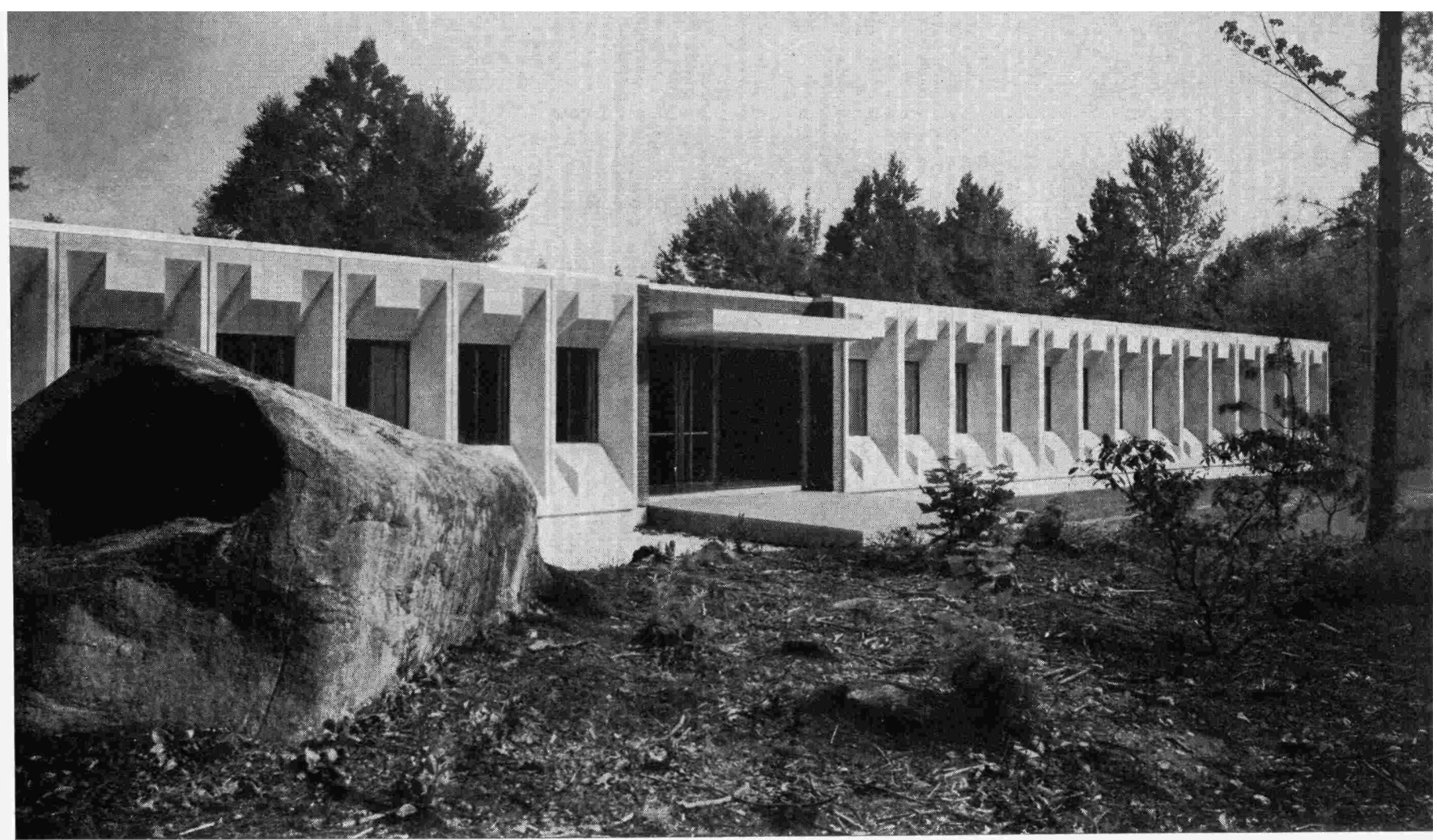

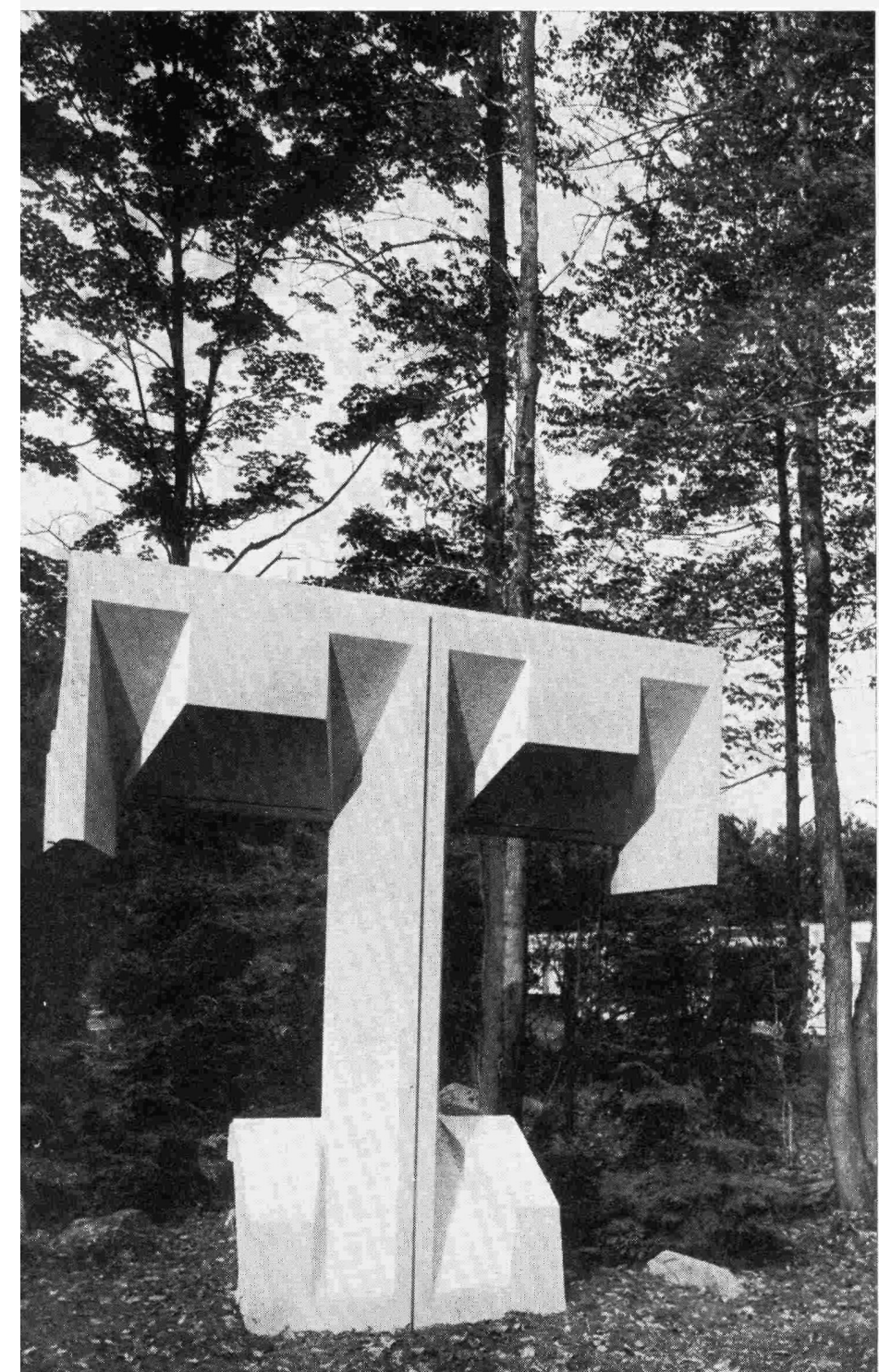

\section{pequeño edificio de oficinas}

\author{
MARCEL BREUER y HERBERT BECKHARD,
}

arquitectos

\title{
simopsis
}

Las formas escultórico-arquitectónicas logradas mediante la adecuada combinación de superficies planas, textura y color de los diferentes materiales empleados, juegos de luces y sombras, etc., han contribuido poderosa y fundamentalmente a que la composición estética de este edificio administrativo resulte atractiva.

Las fachadas constituyen un bello ejemplo de las posibilidades que ofrece, en la edificación, el empleo de muros de cerramiento resistentes construidos a base de unidades prefabricadas de hormigón.

El nuevo edificio administrativo recientemente erigido para la firma «Torrington Manufacturing Company», en Connecticut, es una de las últimas obras del arquitecto Marcel Breuer, y un fiel exponente de su acertada investigación sobre procedimientos para lograr, con muros resistentes construidos a base de elementos prefabricados de hormigón, una belleza y una expresión arquitectónica apropiadas. 
1. Zaquán-2, Recepción,-3, Secretaría del presidente,-4. Despacho del presidente--

5. Sala de conferencias. -6 . Oficina. -7 . Secretarias. -8 . Oficinas.

$\underset{6 \rightarrow \infty}{6 \rightarrow 0}$

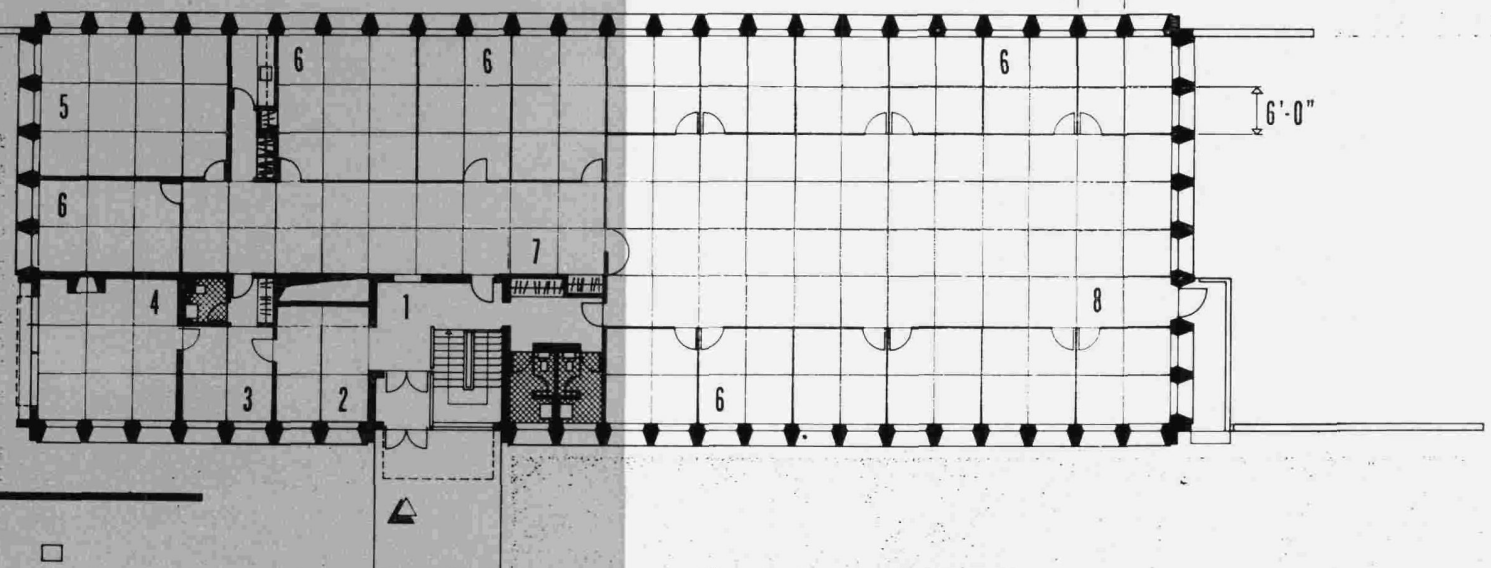

planta alta

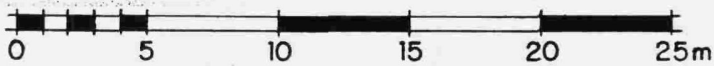

planta baja

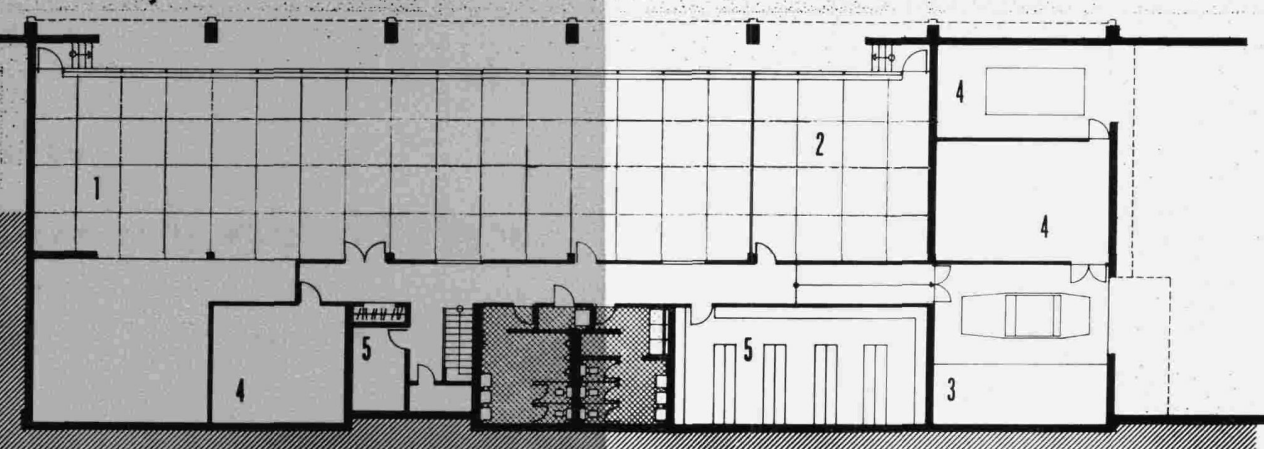

1. Oficinas.-2. Cafeteria.-3. Garaje.-

4. Cuarto de máquinas. -5 . Almacén.
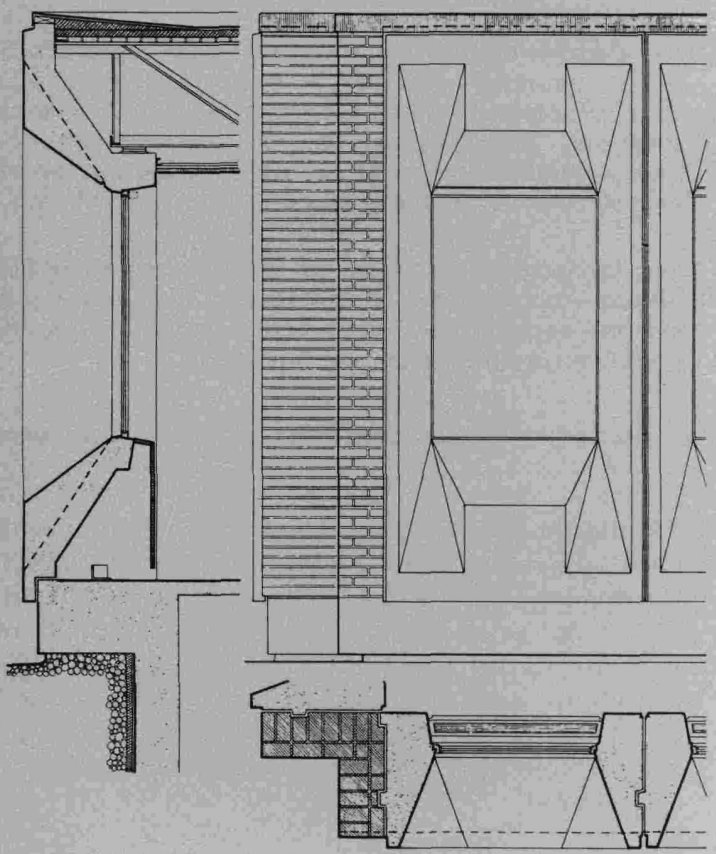

0

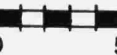

5

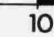

15

Las fachadas están integradas por unidades prefabricadas que, actuando como elementos de cerramiento y resistentes, son portadores al mismo tiempo de: los acabados interior y exterior, y de los equipos eléctricos, mecánicos, etc., correspondientes.

En cuanto a la distribución, la planta noble comprende: un pequeño vestíbulo, zona de recepción, oficina y secretaría del presidente, sala de conferencias, sala de secretarias, amplia zona con la oficina general, aseos, etc.

Debido a la profundidad y configuración del edificio es posible graduar la iluminación y el aislamiento de las diversas dependencias.

Desde el punto de vista de la composición estética, las formas escultórico-arquitectónicas logradas a base de la combinación de superficies 

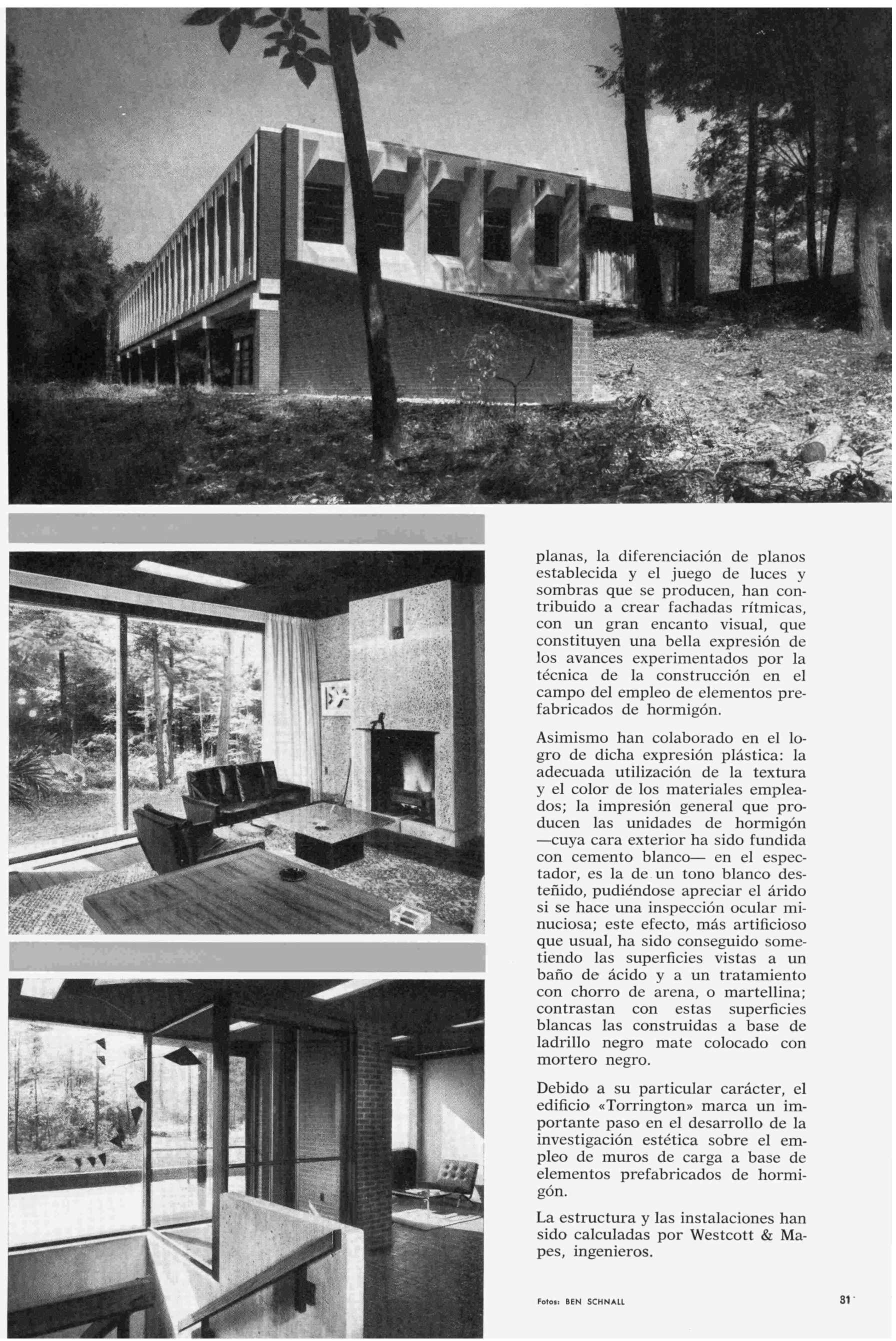

planas, la diferenciación de planos establecida y el juego de luces y sombras que se producen, han contribuido a crear fachadas rítmicas, con un gran encanto visual, que constituyen una bella expresión de los avances experimentados por la técnica de la construcción en el campo del empleo de elementos prefabricados de hormigón.

Asimismo han colaborado en el logro de dicha expresión plástica: la adecuada utilización de la textura y el color de los materiales empleados; la impresión general que producen las unidades de hormigón - cuya cara exterior ha sido fundida con cemento blanco- en el espectador, es la de un tono blanco desteñido, pudiéndose apreciar el árido si se hace una inspección ocular minuciosa; este efecto, más artificioso que usual, ha sido conseguido sometiendo las superficies vistas a un baño de ácido y a un tratamiento con chorro de arena, o martellina; contrastan con estas superficies blancas las construidas a base de ladrillo negro mate colocado con mortero negro.

Debido a su particular carácter, el edificio "Torrington" marca un importante paso en el desarrollo de la investigación estética sobre el empleo de muros de carga a base de elementos prefabricados de hormigón.

La estructura y las instalaciones han sido calculadas por Westcott \& Mapes, ingenieros. 


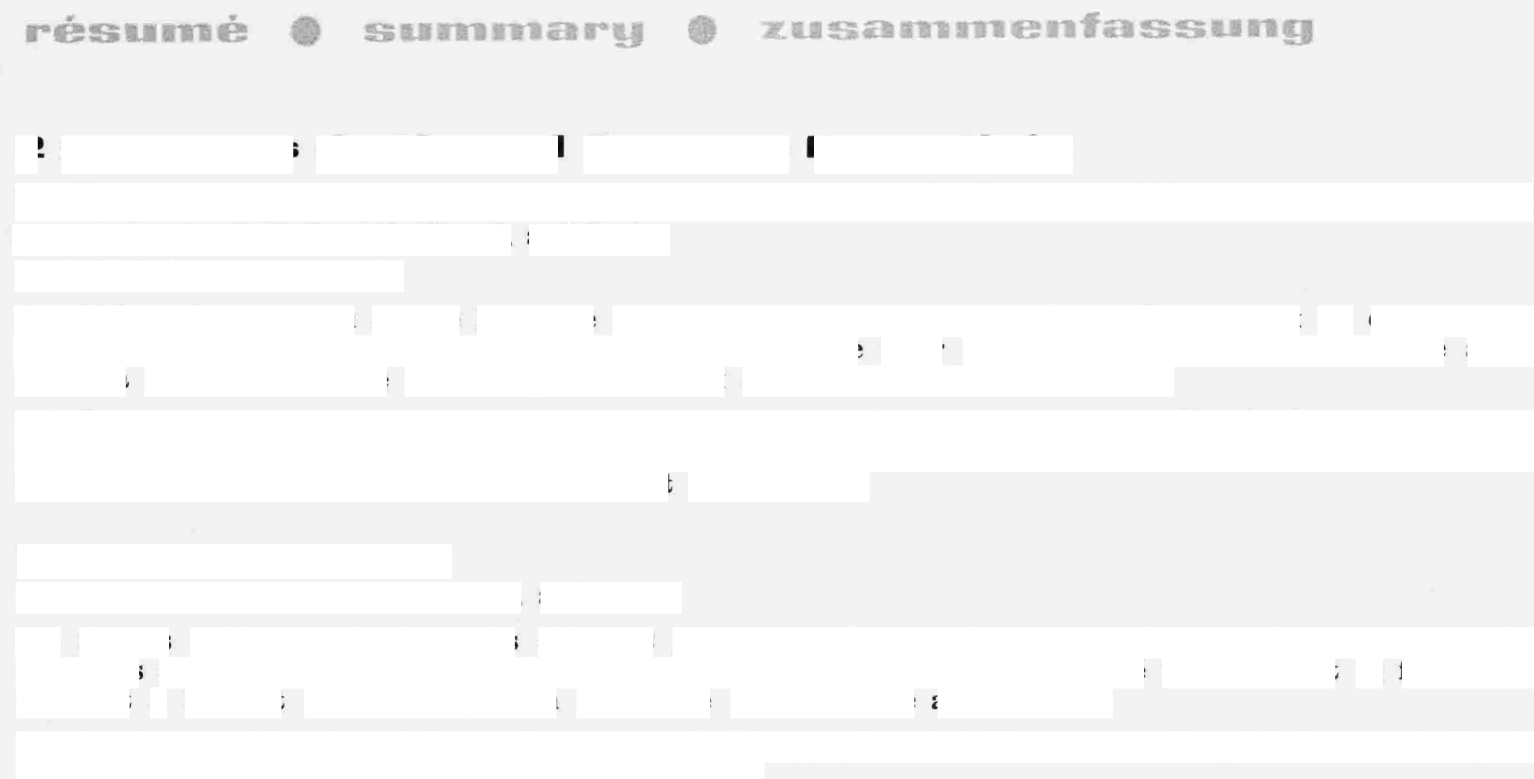

I

$\begin{array}{llllll}1 & 1 & 1 & 1\end{array}$

Small office building

Marcel Breuer \& Herbert Beckhard, architects

The sculpturd architectural shapes obtained by the combination of plane surfaces, and the texture and colour of the various materials employed, as well as the light and shadow effects achieved thereby, have contributed very markedly to the very attractive composition of this administrative building.

The external walls are a fine example of the possibilities of achieving excellent designs using prefabricated concrete units.

!

:
I

Cand 